\title{
Correlation of Doppler assessment of fetal aortic isthmus with perinatal outcome in intrauterine growth restriction
}

\author{
Bhoomika Tantuway'*, Y. M. Mala' ${ }^{2}$ Anju Garg ${ }^{3}, \operatorname{Reva}^{\text {Tripathi }}{ }^{2}$
}

\begin{abstract}
${ }^{1}$ Department of Obstetrics and Gynecology, N.S.C.B Medical College, Jabalpur, Madhya Pradesh, India
${ }^{2}$ Department of Obstetrics and Gynecology, ${ }^{3}$ Department of Radiodiagnosis Maulana Azad Medical College and Associated Lok Nayak Hospital, New Delhi, India
\end{abstract}

Received: 12 July 2018

Accepted: 06 August 2018

\author{
*Correspondence: \\ Dr. Bhoomika Tantuway, \\ E-mail: drbhoomi_2005@yahoo.co.in
}

Copyright: (c) the author(s), publisher and licensee Medip Academy. This is an open-access article distributed under the terms of the Creative Commons Attribution Non-Commercial License, which permits unrestricted non-commercial use, distribution, and reproduction in any medium, provided the original work is properly cited.

\section{ABSTRACT}

Background: The objective of the present study was to find out association between aortic isthmus Doppler changes and perinatal outcome in growth restricted fetuses with placental insufficiency.

Methods: It is a prospective case control study, cases were 43 pregnant women with fetal growth restriction (FGR) with abnormal umbilical artery (UA) Doppler while 43 pregnant women with FGR but normal UA doppler, matched with period of gestation were taken as control. The direction of blood flow in aortic isthmus studied which may be antegrade, absent or retrograde and correlation between qualitative parameters of umbilical artery, aortic isthmus and ductus venosus were studied. Quantitative parameters, PI and RI were also calculated. Patients were managed as per hospital protocols. Perinatal outcome and any adverse event e.g. stillbirth, neonatal death, respiratory distress syndrome, intensive care unit stay $>14$ days etc. was noted.

Results: The number of intrauterine death (IUD) and still birth was increased in women with absent and retrograde flow in aortic isthmus, $66.7 \%$ and $71.4 \%$ respectively ( $\mathrm{p}$ value $<0.001$ ). Retrograde blood flow in the aortic isthmus is consistently associated with absent or reverse end diastolic velocity in umbilical artery and ductus venosus.

Conclusions: Doppler of aortic isthmus is an additional parameter to assess severity of FGR. It plays an important role in termination of preterm FGR fetuses.

Keywords: Aortic isthmus doppler, Doppler studies in fetal growth restriction, Ductus venosus, Intrauterine growth retardation, Still birth, Umbilical artery

\section{INTRODUCTION}

Placental insufficiency and fetal growth restriction (FGR) is associated with antepartum, intrapartum and postpartum complications. To facilitate normal intrauterine growth, remarkable changes occur in the maternal, placental and fetal vasculature. ${ }^{1}$

When this mechanism fails, abnormal vascular resistance patterns develop which lead to compromise of fetus. This can be diagnosed by Doppler studies, which are considered as the gold standard in the management of the growth-restricted fetuses. Fetal Doppler patterns follow a longitudinal trend with sequential changes in umbilical, middle cerebral artery, followed by other peripheral arteries. Venous changes appear later in the severely compromised fetus and usually associated with presence of acidemia.

Doppler reveals changes of hypoxia at least a week before the non-stress test or the biophysical profile. It has therefore become the gold standard in the management of 
the growth-restricted fetus and aids in making decision regarding the appropriate timing of delivery. ${ }^{2-4}$ Fetal aortic isthmus (AoI) is a vascular segment situated between the origin of left subclavian artery and aortic end of ductus arteriosus. It is the only arterial connection between right ventricle (which supplies mainly systemic and placental circulations) and left ventricle (which supplies essentially the cerebral vascular network). ${ }^{4}$ Consequently, its blood flow pattern reflects the balance between ventricular outputs and existence of differences in vascular impedance in either vascular system. ${ }^{5,6}$ Reason for decrease in absolute velocities in aortic isthmus in cases of FGR with placental insufficiency is increase in placental vascular resistance and cerebral vasodilatation.

In FGR with placental insufficiency the diastolic aortic isthmus blood flow may disappear and in very severe cases can become predominantly retrograde. This has led to suggestions of its potential role as a reliable indicator of the progression of fetal hemodynamic deterioration in FGR. Thus, in present study, we tried to correlate aortic isthmus blood flow changes with perinatal outcome in FGR babies as it may play an important role in decision making regarding termination of pregnancy.

\section{METHODS}

A prospective case control study was conducted in the Department of Obstetrics and Gynaecology, Maulana Azad Medical College, New Delhi, from October 2011 to March 2013 after the approval of the institutional review board.

Aim of the study was to find out the association between aortic isthmus Doppler changes and perinatal outcome in growth restricted fetuses with placental insufficiency and to find out the correlation between the qualitative parameters of umbilical artery, aortic isthmus and ductus venosus.

Study group included 50 pregnant women with singleton pregnancy, sure of dates (gestational age confirmed by first trimester scan) and diagnosed to have asymmetrical FGR (FGR, when fetal estimated weight is less than 10th percentile of their expected weight depending on period of gestation in weeks, calculated through ultrasonography) with an abnormal umbilical Doppler study.

But results of 43 patients were analyzed as 7 patients were lost to follow up. Pregnancy with gross congenital anomalies in the fetus were excluded from the study. Recruitment of cases with FGR began after 28 weeks of gestation.

43 pregnant women with intrauterine growth retardation but with normal umbilical artery doppler, matched with period of gestation were taken as control. Informed consent was taken from every patient.
Biometry and Doppler ultrasonography were performed by Philips iU22 xMATRIX ultrasonography machine. In patients with abnormal umbilical Doppler findings further study of blood vessels including middle cerebral artery, ductus venosus and aortic isthmus was performed.

The direction of blood flow in fetal aortic isthmus was studied which may be antegrade, absent or retrograde flow. It was performed during absence of fetal movement in either the longitudinal aortic arch or the three vessels and trachea view. ${ }^{7}$ Peak systolic velocity end diastolic velocity, S/D ratio, Pulsatility index, Resistance index, was calculated in all four studied vessels. S/D ratio and other Doppler parameters of aortic isthmus were compared to existing normogram based on period of gestation.

The results of aortic isthmus Doppler were blinded to the treating obstetrician. The fetal surveillance and Doppler studies were continued once a week or more frequently if required, till decision for delivery was taken as per the hospital protocol.

Following delivery, the birth weight, Apgar score at 1 and $5 \mathrm{~min}$ and umbilical cord arterial $\mathrm{pH}$ of the new born were noted. Perinatal evaluation was done by observing for any complication in the infant and indication of admission in a neonatal intensive care unit (NICU) if any and duration of stay were noted. Perinatal adverse outcome parameters included in the study were: stillbirth, neonatal mortality, bronchopulmonary dysplasia, respiratory distress syndrome, intraventricular hemorrhage, necrotizing enterocolitis (NEC), sepsis and admission in a neonatal intensive care unit longer than 14 days.

The data regarding various Doppler findings were entered in SPSS version 15.0 and was analyzed. The correlation between the qualitative variables was determined by using an unpaired $t$ test. The predictive value of the AoI and other Doppler variables in predicting adverse perinatal outcome was assessed by estimation of sensitivity, specificity and predictive values.

\section{RESULTS}

The results of Doppler parameters of different fetal vessels were correlated with aortic isthmus blood flow and pregnancy outcomes.

It was observed that with increase in severity of Doppler parameters of umbilical artery, aortic isthmus wave forms also became abnormal. Retrograde blood flow in the aortic isthmus is consistently associated with absent or reverse end diastolic velocity in the umbilical artery and ductus venosus.

In $71.4 \%$ fetuses in present study the reversal of flow in aortic isthmus preceded that in the ductus venosus by $24-$ 48 hours. 
Table 1: *Correlation of Doppler parameters in aortic isthmus, umbilical artery and ductus venosus.

\begin{tabular}{|c|c|c|c|c|c|c|c|}
\hline \multicolumn{3}{|c|}{ UA end diastolic flow } & \multirow[t]{2}{*}{$\begin{array}{l}\text { Aortic isthmus } \\
\text { end diastolic } \\
\text { flow }\end{array}$} & \multicolumn{4}{|c|}{ Ductus venosus doppler (a wave) } \\
\hline $\begin{array}{l}\mathrm{S} / \mathrm{D} \text { ratio } \\
\mathrm{n}=7(\%)\end{array}$ & $\begin{array}{l}\text { Absent flow } \\
n=21(\%)\end{array}$ & $\begin{array}{l}\text { Reverse flow } \\
n=15(\%)\end{array}$ & & $\begin{array}{l}\text { Normal } \\
(n=23)(\%)\end{array}$ & $\begin{array}{l}\text { S/A ratio } \\
(n=11)(\%)\end{array}$ & $\begin{array}{l}\text { Absent } \\
(\mathbf{n}=2)(\%)\end{array}$ & $\begin{array}{l}\text { Reverse } \\
(n=7)(\%)\end{array}$ \\
\hline $6(85.7)$ & $6(28.6)$ & 0 & $\begin{array}{l}\text { Antegrade } \\
\mathrm{n}=12\end{array}$ & $12(100)$ & $0(0)$ & $0(0)$ & $0(0)$ \\
\hline $1(14.3)$ & $9(42.9)$ & $1(6.7)$ & $\begin{array}{l}\text { Increased } S / D \\
\text { ratio } \\
n=11\end{array}$ & $8(72.7)$ & $3(27.2)$ & $0(0)$ & $0(0)$ \\
\hline 0 & $5(23.8)$ & $1(6.7)$ & $\begin{array}{l}\text { Absent } \\
n=6\end{array}$ & $2(33.3)$ & $3(50)$ & $1(16.7)$ & $0(0)$ \\
\hline 0 & $1(4.7)$ & $13(86.7)$ & $\begin{array}{l}\text { Retrograde } \\
n=14\end{array}$ & $1(7.1)$ & $5(35.7)$ & $1(7.1)$ & $7(50)$ \\
\hline \multicolumn{4}{|c|}{$\mathrm{P}$ value $<0.001$} & \multicolumn{4}{|c|}{$\mathrm{P}$ value $<0.001$} \\
\hline
\end{tabular}

In present study (Table 2), all patients with normal antegrade flow in fetal aortic isthmus delivered live babies and the risk of IUD increased among patients with absent or retrograde flow in aortic isthmus. Out of 43 women studied 18 had still births.

Table 2: Association of fetal aortic isthmus Doppler findings with still birth.

\begin{tabular}{|c|c|c|c|c|}
\hline \multirow{2}{*}{$\begin{array}{l}\text { Aortic } \\
\text { isthmus } \\
\text { Doppler }\end{array}$} & \multicolumn{3}{|c|}{ Complications } & \multirow[t]{2}{*}{$\begin{array}{l}\text { p } \\
\text { value }\end{array}$} \\
\hline & $\begin{array}{l}\text { Live } \\
\text { birth } \\
(\%)\end{array}$ & $\begin{array}{l}\text { Macerated } \\
\text { still birth } \\
(\%)\end{array}$ & $\begin{array}{l}\text { Fresh } \\
\text { still } \\
\text { birth }\end{array}$ & \\
\hline $\begin{array}{l}\text { Antegrade } \\
\text { flow } \\
(n=12)\end{array}$ & $\begin{array}{l}12 \\
(100)\end{array}$ & 0 & 0 & \multirow{4}{*}{$<0.001$} \\
\hline $\begin{array}{l}\text { S/D ratio } \\
(\mathrm{n}=11)\end{array}$ & $\begin{array}{l}9 \\
(81.8)\end{array}$ & $\begin{array}{l}2 \\
(18.2)\end{array}$ & 0 & \\
\hline $\begin{array}{l}\text { Absent } \\
\text { EDF } \\
(n=6)\end{array}$ & $\begin{array}{l}2 \\
(33.3)\end{array}$ & $\begin{array}{l}4 \\
(66.6)\end{array}$ & 0 & \\
\hline $\begin{array}{l}\text { Retrograd } \\
\text { e flow } \\
(n=14)\end{array}$ & $\begin{array}{l}2 \\
(14.2)\end{array}$ & $\begin{array}{l}10 \\
(71.4)\end{array}$ & $\begin{array}{l}2 \\
(14.2)\end{array}$ & \\
\hline
\end{tabular}

The remaining 25 babies were observed for development of complication. All neonates developed more complications when there was absent, retrograde flow of umbilical artery, ductus venous and aortic isthmus.

The specificity and positive predictive value of aortic isthmus Doppler parameters when evaluated for an adverse perinatal outcome was $100 \%$.

The specificity and positive predictive value for mortality was highest with abnormal aortic isthmus and ductus venosus Doppler when compared to umbilical or middle cerebral artery.

\section{DISCUSSION}

Fetal growth restriction (FGR) is associated with adverse outcome like stillbirth, perinatal morbidity and mortality. Decision for termination and timing of delivery is important to prevent preterm deliveries and on the other hand to prevent exposure of fetus to hypoxic uterine environment. The role of aortic isthmus Doppler in management of growth restricted baby was studied.

In the present study, all patients in control group had antegrade flow in the aortic isthmus. In study group $53.5 \%, 13.9 \%, 32.6 \%$ patients had antegrade, absent and retrograde flow respectively. Retrograde diastolic blood flow in the aortic isthmus signifies redistribution of fetal circulation, indicating lower cerebral resistance. ${ }^{8}$

Rio and Martinez have conducted a similar study in preterm IUGR patients and found that aortic isthmus Doppler blood flow has an important role in predicting the severity of placental insufficiency and decision making about termination of pregnancy. They found significant correlation $(\mathrm{P}<0.001)$ between retrograde blood flow in the AoI and adverse perinatal outcome, the overall perinatal mortality being higher in the retrograde group $(70 \%$ vs. $4.8 \%, \mathrm{P}<0.001){ }^{9}$

It was also observed that with increase in severity of abnormality in Doppler parameters of umbilical artery, aortic isthmus wave forms also became abnormal. Patients with absent or reverse end diastolic flow in umbilical artery also showed absent or reverse flow in aortic isthmus.

In women with increase S/D ratio in umbilical artery showed a normal antegrade flow in the aortic isthmus. 
Similar results were found by Fouron JC, Gosselin J. The correlation between aortic isthmus and ductus venosus Doppler was studied and it was observed that all patients with normal antegrade flow in fetal aortic isthmus had normal ductus venosus Doppler.

Table 3: Correlation of Doppler study in different fetal vessels with neonatal complications.

\begin{tabular}{|c|c|c|c|c|c|c|c|c|c|}
\hline \multirow[t]{2}{*}{$\begin{array}{l}\text { Doppler } \\
\text { Parameters }\end{array}$} & \multicolumn{8}{|c|}{ Complications* } & \multirow[t]{2}{*}{$\begin{array}{l}\text { p } \\
\text { value }\end{array}$} \\
\hline & None & $\begin{array}{l}\text { NICU stay } \\
>14 \text { days }\end{array}$ & RDS & NEC & Sepsis & $\begin{array}{l}\text { Ventilation } \\
\text { required }\end{array}$ & $\begin{array}{l}\text { Neonatal } \\
\text { death }\end{array}$ & $\begin{array}{l}\text { Failure to } \\
\text { resuscitate }\end{array}$ & \\
\hline \multicolumn{10}{|l|}{$\begin{array}{l}\text { Umbilical artery } \\
\mathrm{n}=25\end{array}$} \\
\hline $\begin{array}{l}\text { Increase S/D } \\
\text { ratio } n=7\end{array}$ & 4 & 3 & 0 & 0 & 1 & 0 & 0 & 0 & \multirow{3}{*}{0.04} \\
\hline $\begin{array}{l}\text { Absent EDF } \\
n=15\end{array}$ & 2 & 12 & 2 & 1 & 4 & 4 & 3 & 0 & \\
\hline $\begin{array}{l}\text { Reverse EDF } \\
n=3\end{array}$ & 0 & 2 & 2 & 0 & 1 & 0 & 0 & 1 & \\
\hline \multicolumn{10}{|l|}{$\begin{array}{l}\text { Middle cerebral } \\
\text { artery } n=25\end{array}$} \\
\hline $\begin{array}{l}\text { Normal S/D ratio } \\
\mathrm{n}=2\end{array}$ & 2 & 0 & 0 & 0 & 0 & 0 & 0 & 0 & \\
\hline $\begin{array}{l}\text { Increase } S / D \\
\text { ratio } n=23\end{array}$ & 4 & 17 & 4 & 1 & 6 & 4 & 3 & 1 & 0.05 \\
\hline \multicolumn{10}{|l|}{$\begin{array}{l}\text { Aortic isthmus } \\
n=25\end{array}$} \\
\hline $\begin{array}{l}\text { Normal AI } \\
\text { doppler } n=12\end{array}$ & 6 & 6 & 1 & 0 & 2 & 2 & 1 & 0 & \multirow{4}{*}{0.03} \\
\hline $\begin{array}{l}\text { Increase } S / D \\
\text { ratio } n=9\end{array}$ & 0 & 8 & 1 & 1 & 3 & 2 & 2 & 0 & \\
\hline Absent EDF n=2 & 0 & 2 & 1 & 0 & 1 & 0 & 0 & 0 & \\
\hline Reverse EDFn=2 & 0 & 1 & 1 & 0 & 0 & 0 & 0 & 1 & \\
\hline \multicolumn{10}{|l|}{$\begin{array}{l}\text { Ductus venosus } \\
\mathrm{n}=25\end{array}$} \\
\hline $\begin{array}{l}\text { Normal DV } \\
\text { doppler } \mathrm{n}=21\end{array}$ & 6 & 15 & 2 & 1 & 4 & 3 & 2 & 0 & \multirow{4}{*}{0.68} \\
\hline $\begin{array}{l}\text { Increase S/A } \\
\text { ratio } n=3\end{array}$ & 0 & 2 & 2 & 0 & 2 & 1 & 1 & 0 & \\
\hline $\begin{array}{l}\text { Absent a wave } \\
\mathrm{n}=0\end{array}$ & 0 & 0 & 0 & 0 & 0 & 0 & 0 & 0 & \\
\hline $\begin{array}{l}\text { Reverse a wave } \\
n=1\end{array}$ & 0 & 0 & 0 & 0 & 0 & 0 & 0 & 1 & \\
\hline
\end{tabular}

*Individual neonate had more than one complication; hence " $n$ " does not correspond with total number of complications in each group.

Most of the patients with absent or retrograde flow in aortic isthmus also developed absent or reverse flow in ductus venosus later. E. Ferrazzi and M. Bozzo studied correlation of Doppler blood flow in various vessels in IUGR babies. They concluded that, severely growthrestricted fetuses followed a progressive sequence of acquiring Doppler abnormalities which were categorized into 'early' and 'late' Doppler changes.

Early changes occurred in peripheral vessels (umbilical and middle cerebral arteries; $50 \%$ of patients affected 15 16 days prior to delivery). Late changes included umbilical artery reverse flow, and abnormal changes in the ductus venosus, aortic and pulmonary outflow tracts ( $50 \%$ of patients affected $4-5$ days prior to delivery). The time interval between the occurrence of early and late changes was significantly different $(\mathrm{P}<0.001)$. Another study also observed that ductus venosus abnormality was associated with cardiovascular deterioration of the fetus and Aortic isthmus Doppler abnormality occurred prior to ductus venosus. ${ }^{10}$ They concluded that abnormal aortic isthmus impedance indices are an intermediate step between placental insufficiency-hypoxemia and cardiac decompensation. 
In the present study, a significant association was found with abnormal umbilical artery Doppler and still birth. With increasing severity of umbilical artery risk of IUD and still birth also increased. Risk of fresh still birth was highest $(21.4 \%)$ in fetuses with retrograde flow in aortic isthmus. Therefore, overall mortality was significantly higher in babies with absent or retrograde flow in aortic isthmus ( $\mathrm{p}$ value $<0.001$ ). A study conducted by Hidar $\mathrm{S}$ et al in 2004 also showed that there was an increase in perinatal mortality in babies with retrograde blood flow in aortic isthmus. ${ }^{11}$

Table 4: Predictive value of fetal aortic isthmus and other Doppler parameters evaluated for an adverse perinatal outcome.

\begin{tabular}{|c|c|c|c|c|}
\hline Doppler parameters & $\begin{array}{l}\text { Sensitivity } \\
{[\%(n)]}\end{array}$ & $\begin{array}{l}\text { Specificity } \\
{[\%(n)]}\end{array}$ & $\begin{array}{l}\text { PPV } \\
{[\%(\mathbf{n})]}\end{array}$ & $\begin{array}{l}\text { NPV } \\
{[\%(\mathbf{n})]}\end{array}$ \\
\hline \multicolumn{5}{|l|}{ Umbilical artery } \\
\hline Increase $S / D$ ratio & $15.7(3 / 19)$ & $33.3(2 / 6)$ & $42.8(3 / 7)$ & $11.1(2 / 18)$ \\
\hline Absent flow & $68.4(13 / 19)$ & $66.6(4 / 6)$ & $86.6(13 / 15)$ & $40(4 / 10)$ \\
\hline Reverse flow & $15.7(3 / 19)$ & $100(6 / 6)$ & $100(3 / 3)$ & $27.2(6 / 22)$ \\
\hline \multicolumn{5}{|l|}{ Aortic isthmus } \\
\hline Antegrade flow & $31.5(6 / 19)$ & $0(0 / 6)$ & $50(6 / 12)$ & $0(0 / 13)$ \\
\hline Increased S/D ratio & $47.3(9 / 19)$ & $100(6 / 6)$ & $100(9 / 9)$ & $34.5(6 / 16)$ \\
\hline Absent flow & $10.5(2 / 19)$ & $100(6 / 6)$ & $100(2 / 2)$ & $26.08(6 / 23)$ \\
\hline Retrograde flow & $10.5(2 / 19)$ & $100(6 / 6)$ & $100(2 / 2)$ & $26.08(6 / 23)$ \\
\hline \multicolumn{5}{|l|}{ Ductus venosus } \\
\hline Normal DV doppler & $78.9(15 / 19)$ & $0(0 / 6)$ & $71.4(15 / 21)$ & $0(0 / 4)$ \\
\hline Increase S/A ratio & $15.8(3 / 19)$ & $100(6 / 6)$ & $100(3 / 3)$ & $27.2(6 / 22)$ \\
\hline Absent a wave & $0(0 / 19)$ & $100(6 / 6)$ & $-(0 / 0)$ & $24(6 / 25)$ \\
\hline Reverse a wave & $5.2(1 / 19)$ & $100(6 / 6)$ & $100(1 / 1)$ & $25(6 / 24)$ \\
\hline
\end{tabular}

Table 5: Predictive value of fetal aortic isthmus and other Doppler parameters evaluated for mortality

\begin{tabular}{|c|c|c|c|c|}
\hline Doppler parameters & $\begin{array}{l}\text { Sensitivity } \\
{[\%(\mathbf{n})]}\end{array}$ & $\begin{array}{l}\text { Specificity } \\
{[\%(n)]}\end{array}$ & $\begin{array}{l}\text { PPV } \\
{[\%(\mathbf{n})]}\end{array}$ & $\begin{array}{l}\text { NPV } \\
{[\%(\mathbf{n})]}\end{array}$ \\
\hline \multicolumn{5}{|l|}{ Umbilical artery } \\
\hline Increase $\mathrm{S} / \mathrm{D}$ & $0(0 / 18)$ & $72(18 / 25)$ & $0(0 / 7)$ & $50(18 / 36)$ \\
\hline Absent flow & $33.3(6 / 18)$ & $40(10 / 25)$ & $28.5(6 / 21)$ & $45.45(10 / 22)$ \\
\hline Reverse flow & $66.6(12 / 18)$ & $88(22 / 25)$ & $80(12 / 15)$ & $78.5(22 / 28)$ \\
\hline \multicolumn{5}{|l|}{ Middle cerebral artery } \\
\hline Abnormal MCA Increase S/D ratio & $100(18 / 18)$ & $8(2 / 25)$ & $43.9(18 / 41)$ & $100(2 / 2)$ \\
\hline \multicolumn{5}{|l|}{ Aortic isthmus } \\
\hline Antegrade flow & $0(0 / 18)$ & $52(13 / 25)$ & $0(0 / 12)$ & $41.9(13 / 31)$ \\
\hline Increase $S / D$ ratio & $11.1(2 / 18)$ & $64(16 / 25)$ & $18.1(2 / 11)$ & $50(16 / 32)$ \\
\hline Absent flow & $22.2(4 / 18)$ & $92(23 / 25)$ & $66.6(4 / 6)$ & $62.1(23 / 37)$ \\
\hline Retrograde flow & $66.6(12 / 18)$ & $92(23 / 25)$ & $85.712 / 14)$ & $79.3(23 / 29)$ \\
\hline \multicolumn{5}{|l|}{ Ductus venosus } \\
\hline Normal DV Doppler & $11.1(2 / 18)$ & $16(4 / 25)$ & $8.6(2 / 23)$ & $20(4 / 20)$ \\
\hline Increase $S / A$ ratio & $44.4(8 / 18)$ & $88(22 / 25)$ & $72.7(8 / 11)$ & $68.8(22 / 32)$ \\
\hline Absent a wave & $11.1(2 / 18)$ & $100(25 / 25)$ & $100(6 / 6)$ & $60.9(25 / 41)$ \\
\hline Reverse a wave & $33.3(6 / 18)$ & $96(24 / 25)$ & $85.7(6 / 7)$ & $66.6(24 / 36)$ \\
\hline
\end{tabular}

According to Marianne Eronen et al absent or reverse end diastolic flow velocity, particularly with the appearance of reverse diastolic flow in the isthmus of the aortic arch, is a predictor of poor neonatal outcome. Present study results were similar with respect to association of absent or reverse flow in aortic isthmus with perinatal mortality. The positive predictive value of aortic isthmus abnormal Doppler parameters for adverse perinatal outcome was found to be $100 \%$. It was also observed that ductus venosus Doppler parameters were also very specific and its positive predictive value for mortality was also very high. Similar results were also observed by $\mathrm{M}$ Rio et al. ${ }^{9}$ Decision for termination of pregnancy could not be taken based on ductus venosus abnormal Doppler parameters, because change in ductus venosus were associated with acidosis in the fetus. Similar results were found by F. 
Figueras and according to them the duration between abnormality in Doppler to delivery is 24 days, 20 days, 13 days and 1 week in umbilical, middle cerebral artery, Aortic isthmus and ductus venosus respectively. ${ }^{12}$ Therefore, Doppler abnormality of different vessels showed an almost linear deterioration throughout monitoring. Hence aortic isthmus blood flow can be used to improve current algorithms for the prediction of mortality and long-term neuro-developmental deficit.

There was no significant association between aortic isthmus PI, RI and PSV and still birth, adverse neonatal outcome.

Our observation was in favour that Doppler imaging of aortic isthmus can be used in the clinical surveillance of fetuses with FGR, and even time of termination of the pregnancy can be decided especially in preterm fetuses. Till the flow in aortic isthmus remains antegrade, the baby can be followed with non-stress testing, every alternate day, but with occurrence of abnormality in aortic isthmus i.e. increased $\mathrm{S} / \mathrm{D}$ ratio the decision for termination should be taken for preventing neonatal complications.

Changes in ductus venosus occurs later and if present is associated with high chances fetal acidosis and mortality.

Funding: No funding sources

Conflict of interest: None declared

Ethical approval: The study was approved by the Institutional Ethics Committee

\section{REFERENCES}

1. Adre J. Cerebral blood flow and metabolism in the developing fetus. Clinics Perinatol. 2009;36(3):51330 .

2. Gonzalez J, Stamilio D, Ural S, Macones G, Odibo A. Relationship between abnormal fetal testing and adverse perinatal outcomes in intrauterine growth restriction. Am J Obstet Gynecol. 2007;196(5):e4851.

3. Padmagirison R, Rai L. Fetal Doppler versus NST as predictors of adverse perinatal outcome in severe preeclampsia and fetal growth restriction. J Obstet Gynecol. 2006;56:134-8.
4. Fouron JC. The unrecognized physiological and clinical significance of the fetal aortic isthmus. Ultrasound Obstet Gynecol. 2003;22(5):441-7.

5. Fouron JC, Skoll A, Sonesson SE, Pfizenmaier M, Jaeggi E, Lessard M. Relationship between flow through the fetal aortic isthmus and cerebral oxygenation during acute placental circulatory insufficiency in ovine fetuses. Am J Obstet Gynecol. 1999;181(5):1102-7.

6. Makikallio K, Jouppila P, Rasanen J. Retrograde aortic isthmus net blood flow and human fetal cardiac function in placental insufficiency. Ultrasound Obstet Gynecol 2003;22(4):351-7.

7. Rizzo G, Capponi A, Vendola M, Pietrolucci ME, Arduini D. Use of the 3-vessel view to record Doppler velocity waveforms from the aortic isthmus in normally grown and growth-restricted fetuses: comparison with the long aortic arch view. J Ultra Med. 2008;27(11):1617-22.

8. Acharya G. Technical aspects of aortic isthmus Doppler velocimetry in human fetuses. Ultrasound Obstet Gynecol. 2009;33(6):628-33.

9. M Rio M, Martinez JM, Figueras F, Bennasar M, Olivella A, Palacio M, et al. Doppler assessment of the aortic isthmus and perinatal outcome in preterm fetuses with severe intrauterine growth restriction. Ultrasound Obstet Gynecol. 2008;31(1):41-7.

10. Baschat AA. Ductus venosus Doppler for fetal surveillance in high-risk pregnancies. Clin Obstet Gynecol. 2010;53(4):858-68.

11. Hidar S, Zaafouri R, Bouquizane S, Chaieb A, Jerbi M, Bibi M, Khairi H. Prognostic value of fetal aortic isthmus Doppler waveform in intrauterine growth retardation: prospective longitudinal study. J Obstet Boil Reprod Paris. 2004;33(8):745-52.

12. Figuera F, Benavides A, Del Rio M, Crispi F, Eixarch E, Martinez J et al. Monitoring of fetuses with intrauterine growth restriction: Longitudinal changes in ductus venosus and aortic isthmus flow. Ultrasound Obstet Gynecol. 2009;33(1):39-43.

Cite this article as: Tantuway B, Das V, Mala YM, Garg A, Tripathi R., Correlation of Doppler assessment of fetal aortic isthmus with perinatal outcome in intrauterine growth restriction. Int J Reprod Contracept Obstet Gynecol 2018;7:3780-5. 